\title{
HEAT ABSORPTION PROPERTIES OF GROUND MATERIAL FOR SOLAR CHIMNEY POWER PLANTS
}

\author{
SUNDUS S. AL-AZAWIEY \& S. B. HASSAN \\ Mechanical Engineering Department, Universiti Teknologi PETRONAS, 32610 Bandar Seri Iskandar, Malaysia
}

\begin{abstract}
One of the major challenges to the widespread application of the solar chimney power plant is its low-power conversion efficiency because of the three technological processes involved. The chimney efficiency is difficult to improve, and thus enhancing the collector or turbine performance can considerably improve the total plant efficiency. This work focused on enhancing the energy conversion efficiency of the collector and also extending the operation time using a heat storage medium. The solar to thermal conversion and thermal storage capabilities of six ground materials that are potentially available in Malaysia were studied experimentally and numerically. The experimental model was designed such that the six materials were exposed to the same operation boundary conditions. The numerical studies were conducted using ANSYS software, where the geometrical models were developed and simulated using FLUENT for the fluid flow and energy/thermal field studies. The selected ground materials were ceramic, black stones, sawdust, dark-green painted wood, sand, and pebbles. The simulation and experimental results are in good agreement in terms of air stream velocity and energy conversion efficiency. The results showed that the different materials have different heat storage capacities, and that ceramics extend the operation with improved efficiency until nighttime. The results also showed that ceramic and black stones have better performance than the other materials. However, black stones are recommended as the absorbing material for solar chimney power plants in Malaysia and regional countries because they are readily available.

Keywords: absorption materials energy conversion, absorptivity, convective heat transfer, solar chimney, solar energy.
\end{abstract}

\section{Nomenclature}

\begin{tabular}{ll}
\hline$A$ & Area $\left[\mathrm{m}^{2}\right]$ \\
$\mathrm{b}_{\mathrm{p}}$ & Heat Penetration Coefficients $\left[\mathrm{Ws}^{1 / 2} / \mathrm{K} \cdot \mathrm{m}^{2}\right]$ \\
$c_{p}$ & Specific heat $[\mathrm{kJ} / \mathrm{kg} \cdot \mathrm{K}]$ \\
$h_{c}$ & Convection heat transfer cofficent $\left[\mathrm{W} / \mathrm{m}^{2} . \mathrm{K}\right]$ \\
$h_{r}$ & Radiation heat transfer cofficent $\left[\mathrm{W} / \mathrm{m}^{2} . \mathrm{K}\right]$ \\
$I$ & Solar radiation $\left[\mathrm{W} / \mathrm{m}^{2}\right]$ \\
$\dot{m}$ & Mass flow rate $[\mathrm{kg} / \mathrm{s}]$ \\
$Q_{u}$ & Useful energy $[\mathrm{kJ} / \mathrm{s}]$ \\
$\Delta T$ & Temperatures difference $\left[{ }^{\circ} \mathrm{C}\right]$ \\
$u$ & Velocity in X- direction $[\mathrm{m} / \mathrm{s}]$ \\
$v$ & Velocity in Y- direction $[\mathrm{m} / \mathrm{s}]$ \\
$x, y$ & Coordinates \\
Greek Symbol & \\
$\eta_{\text {collector }}$ & Collector efficiency \\
$\rho$ & Density $\left[\mathrm{kg} / \mathrm{m}^{3}\right]$ \\
$\mu$ & Dynamic viscosity of air $[\mathrm{kg} / \mathrm{ms}]$ \\
$\lambda$ & Thermal conductivity $[\mathrm{W} / \mathrm{m} \mathrm{K}]$ \\
\hline
\end{tabular}




\section{INTRODUCTION}

The solar chimney power plant (SCPP) is proposed as a device that can economically generate electricity from solar energy in a large scale for the future. The performance of the SCPP is a product of the efficiency of the collector, chimney, and turbines. The solar collector plays an important role in converting solar radiation to thermal energy using the absorber. In the traditional SCPP, the ground acts as the absorbing medium, and thus the properties of the ground affect the efficiency of the collector. The choice of ground material in the collector is the key to assuring good collector performance. Ground temperature in the collector will rise when ground absorptivity is enhanced. In general, the efficiency of the SCPP is low and has been reported to be less than 2\% [1-3]. The promising potentials of SCPP have propelled several researchers to solve the challenges associated with the low efficiency of the plant. Some enhancement techniques have also been proposed. Chikere et al. [4] reviewed the enhancement of the SCPP and suggested a modified SCPP integrated with flue gas as a supplementary source of heat. Al-Kayiem et al. [5] and Al-Kayiem [6] presented the experimental and numerical results of a modified SCPP integrated with an external auxiliary thermal source. They concluded that considerable enhancement was achieved in the performance of the integrated system, and the SCPP was able to produce electricity during daytime and night time because of the continuous heat supply to the absorber. To enhance collector performance.

\subsection{Experimental attempts}

Some experimental investigations have been conducted by different researchers. Shyia [7] conducted experimental and theoretical studies on the SCPP collector enhancement in Baghdad. She considered five types of ground as the absorbing medium: aggregates, soil, sand underneath, asphalt soil, and asphalt aggregate, where asphalt aggregate offered best absorption. Kreetz [8] introduced the use of a water-filled tight tube as heat storage medium in the collector to improve the collector performance and night operation of the SCPP. Bernardes [9] investigated the possibility of using a water-filled tube on the collector floor as a heat storage medium and found an increase in the power output after sunset. Huang et al. [10] presented a detailed description of the experimental process on thermal storage material for enhancing the solar collector. The work employed two experimental modifications in the collector: (1) the use of pebbles and (2) the introduction of water tubes with a black surface, as well as the integration of the pebbles and the water tubes.

Miqdam and Hussein [11] conducted an experimental investigation on different materials for the collector absorber/basement and its effect on buoyant air temperatures. Three ground types, i.e. concrete, black concrete and black pebbles, were investigated. Bugutekin [12] experimentally investigated the temperature and air velocity distribution in the collector of the SCPP for a special layered soil as an absorbing medium. The results showed that the temperature and velocity were influenced by the heat stored in the ground. Motsamai et al. [13] experimentally investigated the performance of an SCPP collector by employing blackpainted granite rocks as the absorber/thermal energy storage medium.

\subsection{Numerical attempts}

Some numerical studies also reported the performance enhancement of the SCPP collector, such as that of Pastohr et al. [14] who conducted a two-dimensional steady-state 
numerical simulation study on a solar chimney with energy storage. The researchers obtained the distribution of velocity, pressure, and temperature in the collector. Pertorius and Kröger [15] evaluated the influence of collector roof glass and various types of the soil on the performance of a large-scale SCPP. The simulation models that employed limestone and sandstone soil produced virtually similar results to the original model that used granite-based models. Ming et al. [16] analyzed the characteristics of the heat transfer and air flow in the SCPP system with an energy storage layer. Different mathematical models for the collector, chimney, and energy storage layer have been established, and the effect of solar radiation on the heat storage characteristics of the energy storage layer has been analyzed. To study the performance of an SCPP numerically, Zheng et al. [17] carried out their analysis by using simulation and mathematical models to describe the flow and heat transfer mechanisms of the collector, chimney, and energy storage layer. The responses of different energy storage materials to solar radiation and the effect of these materials on the power output with different solar radiations were also analyzed. Zhou et al. [18] chose paraffin as the material of the energy storage layer. An unsteady conjugate numerical study of the system was performed by using FLUENT software. The operational condition of the system was simulated when the solar radiation value was changed with time according to the actual situation. The system had an output of power at night because the energy storage effect of the phase changed the materials. Moreover, because of the working conditions of the heat storage layer, in the same conditions as the solar radiation, the air velocity and maximum output of the power increased with the extension of the operational days of the system. Hurtado et al. [19] analyzed the thermodynamic behavior and power output of an SCPP over a daily operational cycle through numerical modeling under non-steady conditions using soil as a heat storage system. Azeemuddin et al. [20] and Azeemuddin et al. [21] used ANSYS software to numerically simulate an integrated enhancement technique, which uses supplementary heat source from flue gases that flow through conduits embedded in the solar collector, and validated their simulation results with the prototype results obtained by Manzanare. The simulated model showed good performance enhancement and contributed to the reduction of waste heat exhausted to the atmosphere. Al-Azawie et al. [22] considered different types of ground materials and presented the preliminary results of an experimental and numerical study on enhancing SCPP collector performance. They discussed and compared the results of the ground materials and concluded that the ceramic and the stone performed better than the other types of materials.

The SCPP requires a large absorbing area/collector and a gigantic chimney to become economically viable (2). The absorptivity of the collector absorber is of high importance in the performance of the SCPP collector, and thus selecting a suitable type of ground material from the ones that are potentially available is vital in gaining the maximum available energy in the collector. In the present work, which experimentally and numerically extend the work presented by Al-Azawie et al. [22]. The absorptivity of different types of ground materials was studied. These materials are readily available locally in Malaysia for use as ground material for the SCPPs. The different types of ground materials were subjected to a similar environment and their absorptivity were measured based on the temperature and velocity of the outlet air at the top of the chimney-like model. The experimental results were compared with numerical results obtained from simulation using ANSYS software. 


\section{EXPERIMENTAL WORK}

\subsection{Experimental setup}

The experimental model design consists of green-painted wood blocks of $10 \mathrm{~mm}$ - thickness for the collector and chimney walls. It was partitioned into six channels where the different ground materials were displayed at the collector areas separately. At the collector, the top surface was made of $3 \mathrm{~mm}$-thick glass and tilted at $4^{\circ}$ from the ground level for dust and rain so that the surface could self-clean. In the experimental model, the chimney was placed at the end collector and partitioned to meet the partitioning of the collector, such that the air flow of each partition would separate and the temperatures could be measured without interference. Figure 1 shows the schematic of the experimental apparatus. The six types of ground materials studied were dark-green painted wood (DGPW), stones, pebbles, ceramic, sand, and sawdust, all of which were packed to a thickness of $20 \mathrm{~mm}$ each.

\subsection{Instrumentations and measurements}

The temperatures of the materials in the collector, air temperatures at the different partitions of the collector and chimney, and ambient air temperature were measured using Type-K thermocouples and the data acquisition system Graphtec GL800, which has 20 channels for sensor connections, as shown in Fig. 2 the buoyant air velocities of the various partitions at the chimney exit were measured using a digital vane anemometer and a portable hot-wire anemometer model, TPI 575C1 Digital Vane/Hotwire Anemometer, with a digital reader. The ambient wind speed was measured at the location. The global solar radiation was measured using a digital solar meter.

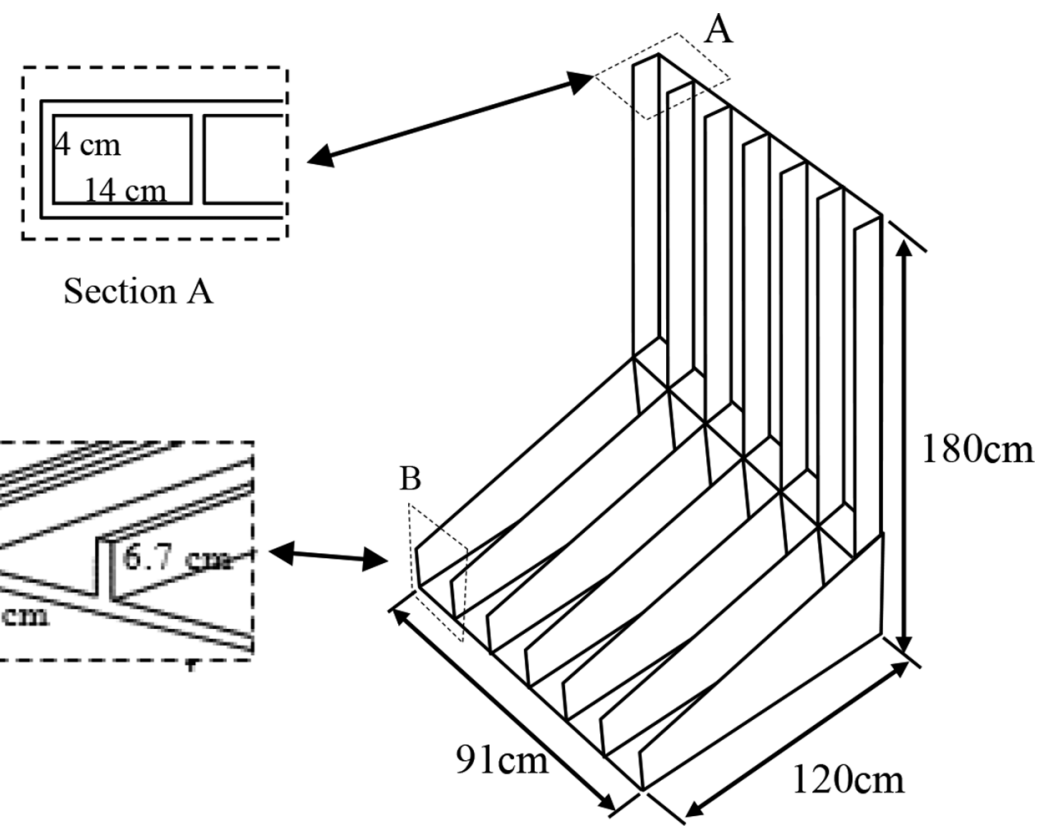

Figure 1: Outlines of the experimental setup. 


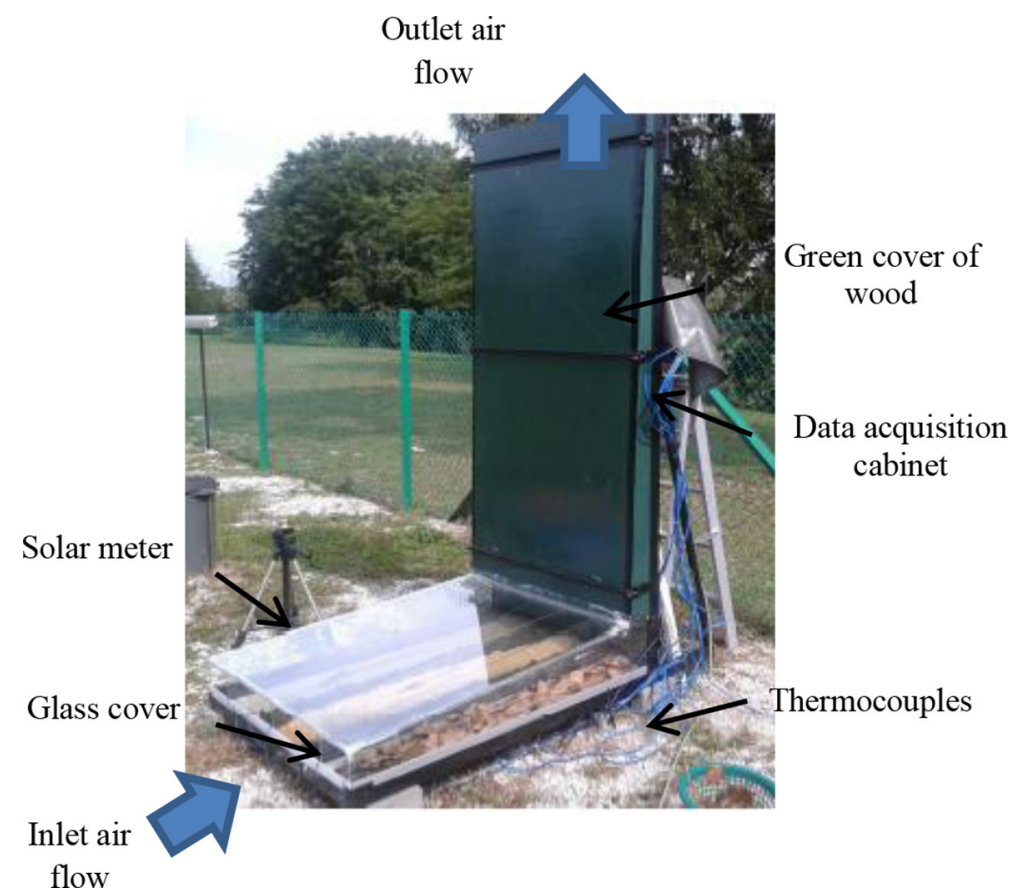

Figure 2: The experimental apparatus.

\subsection{Measurement procedure}

A total of 19 calibrated thermocouples were fixed to measure various air temperatures at different points in the system. Six thermocouples were installed at the collector inlet (one thermocouple for each partition). Six thermocouples were also installed at the collector exit/ chimney base to measure the temperature exiting the chimney from the various partitions. Another six thermocouples were installed at the chimney exit, while one thermocouple was installed at the ambient to measure the ambient temperature. The temperatures in the collector, chimney, and ambient were recorded from 8:00 am to 6:00 pm for 5 days. Radiation intensity and outlet air velocity from the chimney were also measured. The global solar radiation data were captured on minute bases using pyranometer installed at the solar research site in the university. The outlet air velocity was measured using a hot-wire probe connected to a digital anemometer.

The set of equations used to predict the results from the experimental measurements are presented below. The energy absorbed/useful energy gained by the ground material in the collector is evaluated using eqn (1).

$$
Q_{u}=\dot{m} c_{p} \Delta T
$$

Energy supplied to the collector of the system from solar radiation:

$$
Q_{\text {in }}=I \cdot A_{\text {collector }}
$$

Energy conversion efficiency in the collector component of the system: 


$$
\eta_{\text {collector }}=\frac{\dot{m} c_{p} \Delta T}{I \cdot A_{\text {collector }}}
$$

\section{NUMERICAL WORK}

The numerical study involved the use of ANSYS software to determine the characteristics of air flow in the chimney. The study considered the various types of ground materials for the collector, that is, ceramic, stones, sand, pebbles, sawdust, and DGPW. The computational fluid dynamics, CFD, was based on the numerical solutions of the fundamental governing equations of fluid dynamics, the continuity, momentum, and energy. The input data used for the numerical analyses were taken from the experimental investigations.

Navier-Stokes equations were solved using ANSYS-FLUENT software. The procedure involved mesh generation and definition of the boundary conditions for the various faces. The system mesh has 166,764 elements while the flow process was considered for steady-state incompressible flow. The system boundary conditions for the simulations are presented in Table 1.

The physical properties of the fluid were constant; in a similar way that the radiation (emissive properties of the two walls) was neglected, viscous dissipation was neglected as well. The problem was found to be bi-dimensional, permanent, and laminar, thus, the flow process are determined considering mass, momentum and energy equations as shown in eqns (4-6) respectively. The mass/continuity equation for the $2 \mathrm{D}$ flow process is as follows:

$$
\frac{\delta(\rho u)}{\delta x}+\frac{\delta(\rho v)}{\delta x}
$$

Momentum equation, in $x$ - and $y$ - directions:

$$
\begin{aligned}
& x=>\frac{\partial(\rho v u)}{\partial x}+\frac{\partial(\rho u v)}{\partial y}=-\frac{\partial \rho}{\partial x}+\mu\left(\frac{\partial^{2} u}{\partial x^{2}}+\frac{\partial^{2} u}{\partial y^{2}}\right) \\
& y=>\frac{\partial(\rho u v)}{\partial x}+\frac{\partial(\rho v v)}{\partial y}=-\frac{\partial \rho}{\partial y}+\mu\left(\frac{\partial^{2} v}{\partial x^{2}}+\frac{\partial^{2} v}{\partial y^{2}}\right)
\end{aligned}
$$

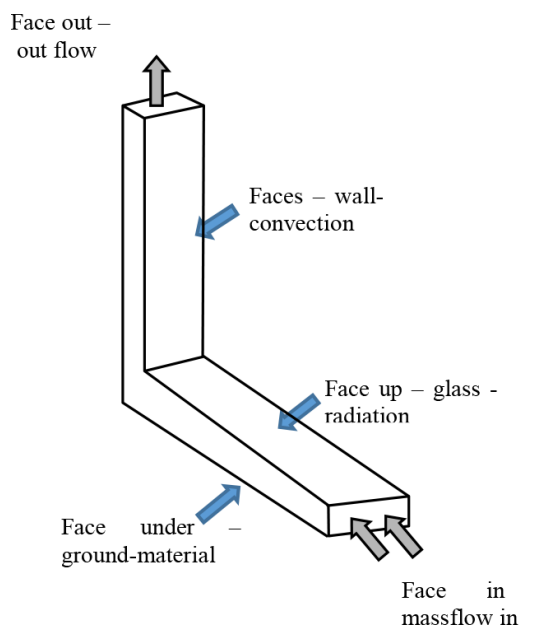

Figure 3: The geometry of the section test drawing and the mesh from the program. 
Table 1: Boundary conditions

\begin{tabular}{|c|c|c|}
\hline Component & Boundary type & Value \\
\hline Ground & Wall & $\begin{array}{l}\mathrm{q}=0 \mathrm{~W} / \mathrm{m}^{2} \text {, No-slip, variable temperature depending } \\
\text { on solar radiation intensity }\end{array}$ \\
\hline Glass & Wall & $\begin{array}{l}\mathrm{q}=0 \mathrm{~W} / \mathrm{m}^{2} \text {, No-slip, variable temperature depending } \\
\text { on solar radiation intensity }\end{array}$ \\
\hline Chimney walls & Wall & $\begin{array}{l}\mathrm{q}=0 \mathrm{~W} / \mathrm{m}^{2} \text {, No-slip, variable temperature depending } \\
\text { on solar radiation intensity }\end{array}$ \\
\hline Collector walls & Wall & $\begin{array}{l}\mathrm{q}=0 \mathrm{~W} / \mathrm{m}^{2}, \text { No-slip, variable temperature depending } \\
\text { on solar radiation intensity }\end{array}$ \\
\hline Collector inlet & Mass-flow inlet & $\begin{array}{l}\dot{m} \text { air-in } \text { and } \mathrm{T}_{\text {air-in }}-\text { variable depending on ambient } \\
\text { condition, }\end{array}$ \\
\hline Chimney & Pressure outlet & $\Delta \mathrm{p}_{\mathrm{o}}=0 \mathrm{~Pa}$ \\
\hline
\end{tabular}

Energy equation:

$$
u \frac{\partial T}{\partial x}+v \frac{\partial T}{\partial y}=\frac{\lambda}{\rho c_{p}}\left(\frac{\partial T^{2}}{\partial x^{2}}+\frac{\partial T^{2}}{\partial y^{2}}\right)
$$

The velocity and temperature for each material were measured from the experimental work at different times during the day (9:00 am, 12:00 pm 3:00 pm, and 6:00 pm).

\section{RESULTS AND DISCUSSION}

\subsection{Analysis of experimental results}

The efficiency of the different materials used as an absorber of the collector is presented in Fig. 4 evaluated using eqn (3). The figure shows that the stones had higher absorptivity of solar radiation during various times of the day, that is, 9:00 am, $12.00 \mathrm{pm}$ and $3.00 \mathrm{pm}$, and gave the best efficiency with the emitted energy. On the other hand, the ceramic material had higher emissivity of solar radiation intensity and lower emissivity at 6:00 pm. According to the data on the performance of the materials after sunset, the ceramic materials released higher stored energy compared with the other materials. The ongoing study will investigate the material with extended performance.

The results also showed that the maximum energy conversion was achieved around 12:00 pm when the maximum solar radiation intensity was recorded at the location. Similarly, after 4:00 pm, when solar radiation intensity was below $320 \mathrm{~W} / \mathrm{m}^{2}$, the total efficiency dropped. The extended performance of all the materials showed that they stored a considerable amount of thermal energy, which was released to the working fluid after sunset. The maximum measured efficiency results are presented in Table 2 and compared with the system efficiency at 12:00 pm and 4:00 pm.

The air mass flow rates generated at the various partitions are presented in Fig. 5. At 12:00 pm, when the solar radiation intensity was $529.3 \mathrm{~W} / \mathrm{m}^{2}$, the dark-green painted wood DGPW had the highest mass flow rate of $0.0715 \mathrm{~kg} / \mathrm{s}$. In contrast, at 2:00 pm, when the solar radiation intensity was $369.3 \mathrm{~W} / \mathrm{m}^{2}$, the stones had the highest mass flow rate of $0.0633 \mathrm{~kg} / \mathrm{s}$. The energy storage potential of the DGPW was low, and most of the energy gained was transferred to the 


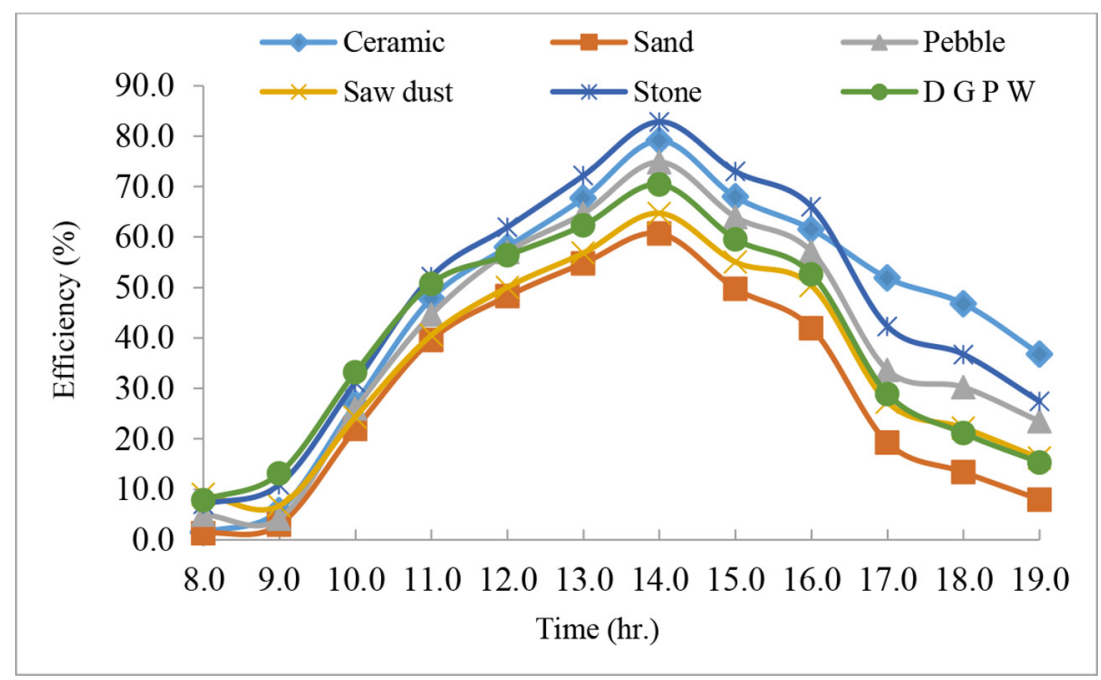

Figure 4: Measured efficiency versus time.

Table 2: Predicted efficiency from the measurements at three different day times.

\begin{tabular}{lccccccc}
\hline Radiation & Time & \multicolumn{7}{c}{ Efficiency $(\%)$} \\
\hline W/m ${ }^{2}$ & Hourly & Ceramic & Sand & Pebbles & Sawdust & Stones & DBPW \\
\hline 529.3 & 12.00 & 58.0 & 48.3 & 57.0 & 50.0 & 62.0 & 56.4 \\
369.3 & 14.00 & 79.1 & 60.7 & 74.8 & 64.7 & 82.8 & 70.5 \\
319.3 & 16.00 & 61.5 & 41.9 & 57.1 & 50.3 & 66.0 & 52.6 \\
\hline
\end{tabular}

working fluid, while the stone showed good absorptivity and emissivity. After 4:00 pm, with the solar radiation of $319.3 \mathrm{~W} / \mathrm{m}^{2}$, the ceramic material had a higher mass flow rate at $0.0400 \mathrm{~kg} / \mathrm{s}$, which showed that it augments the solar radiation input energy with the stored energy.

The temperatures of the different materials at different times of the day are presented in Table 3. As shown in Table 3, the highest temperature was measured for the stone from 9:00 am to 3:00 pm, but the stone temperature was lower than the ceramic temperature at 6:00 $\mathrm{pm}$, which showed that the stone loses its stored energy faster than the ceramics.

\subsection{Heat penetration coefficients}

The following section evaluates the effects of the types of ground on the power production of an SCPP. As shown in Table 4, ceramic, sand and wood were selected from ref. [23-25] according to varying ground, whereas the other materials, such as stone, pebble and sawdust, were selected according to their practically identical heat penetration coefficients $\left(b_{p}=\sqrt{ } \rho c_{p} \lambda\right)$.

\subsection{Numerical results}

The results of the numerical simulations are reported considering the velocity of the working fluid in the system and the temperature field at the different time of the day considering the available solar radiation intensity used in the study. 


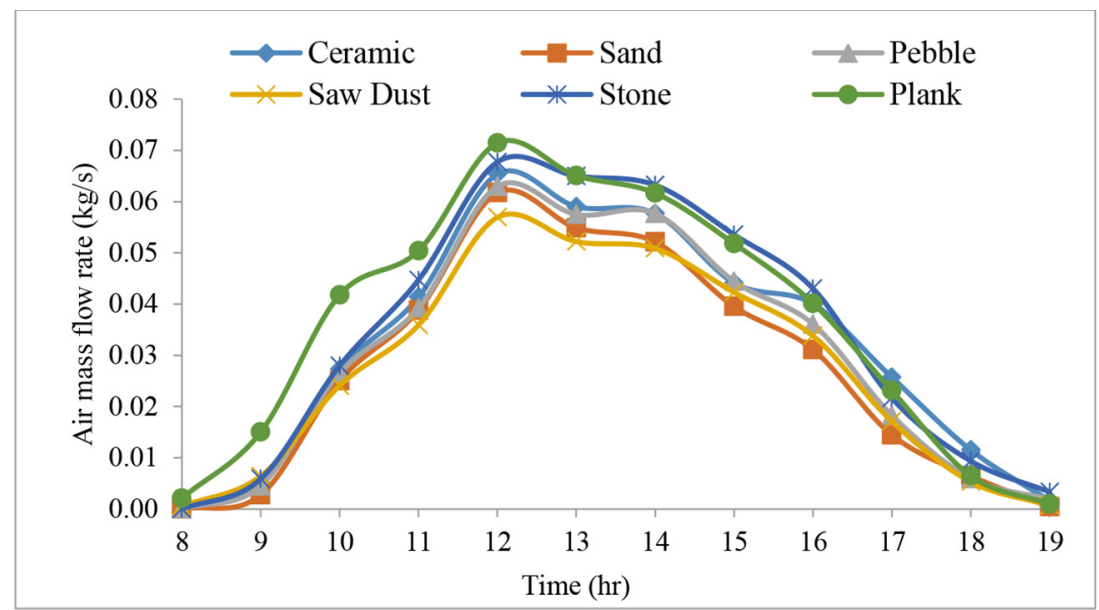

Figure 5: Mass flow rate measured during the experiment time, starting from 8.00 am till $7.00 \mathrm{pm}$.

Table 3: The temperature measurements in intervals of time of the day.

\begin{tabular}{lcrrccc}
\hline Time & Ceramic $\left({ }^{\circ} \mathrm{C}\right)$ & Sand $\left({ }^{\circ} \mathrm{C}\right)$ & Pebble $\left({ }^{\circ} \mathrm{C}\right)$ & Sawdust $\left({ }^{\circ} \mathrm{C}\right)$ & Stone $\left({ }^{\circ} \mathrm{C}\right)$ & D.G.P.W $\left({ }^{\circ} \mathrm{C}\right)$ \\
\hline 9:00 & 27.8 & 27.4 & 27.8 & 28.1 & 28.3 & 29.2 \\
12:00 & 40.9 & 39.4 & 40.7 & 39.7 & 41.1 & 40 \\
15:00 & 39.3 & 37.8 & 39.2 & 38.4 & 40 & 38.9 \\
18:00 & 34.9 & 33.1 & 33.6 & 33.3 & 34.1 & 32.9 \\
\hline
\end{tabular}

Table 4: Average properties of materials.

\begin{tabular}{lcccc}
\hline \multicolumn{5}{c}{ Table 4: Average properties of materials. } \\
$\begin{array}{lcccc}\text { Ground Type } \\
\text { coefficient } b_{\mathrm{p}}\end{array}$ & $\begin{array}{c}\text { Density }\left[\mathrm{kg} / \mathrm{m}^{3}\right] \\
\text { Specific Heat } \\
\text { capacity }[\mathrm{J} / \mathrm{kg} \mathrm{K}]\end{array}$ & $\begin{array}{c}\text { Thermal Conduc- } \\
\text { tivity }[\mathrm{W} / \mathrm{mK}]\end{array}$ & $\begin{array}{c}\text { Heat Penetration } \\
\text { Coefficients } \\
{\left[\mathrm{Ws}^{1 / 2} / \mathrm{Km}^{2}\right]}\end{array}$ \\
\hline Ceramic & 2,700 & 423.62 & 1.5996 & 135.26 \\
Sawdust & 192 & 900 & 0.08 & 117.57 \\
Stone & 2,160 & 710 & 1.83 & $1,675.25$ \\
Pebble & 2,500 & 900 & 1.26 & $1,683.7$ \\
Sand & 1,600 & 708.93 & 0.307 & 590.11 \\
Wood & 802 & 330.67 & 0.8715 & 480.74 \\
\hline
\end{tabular}

\subsubsection{Velocity field}

The velocity contours for each ground material at various times $(9: 00 \mathrm{am}, 12: 00 \mathrm{pm}, 3: 00 \mathrm{pm}$, and 6:00 pm) during the day show that a change in air flow occurred. Figure 6 shows the contours that represent the velocity distribution in the collector and the chimney of the stone material at 9:00 am, 12:00 pm, 3:00 pm, and 6:00 pm. Figure 7 shows the velocity distribution at the chimney inlet [section (A-A)] for each ground material. 


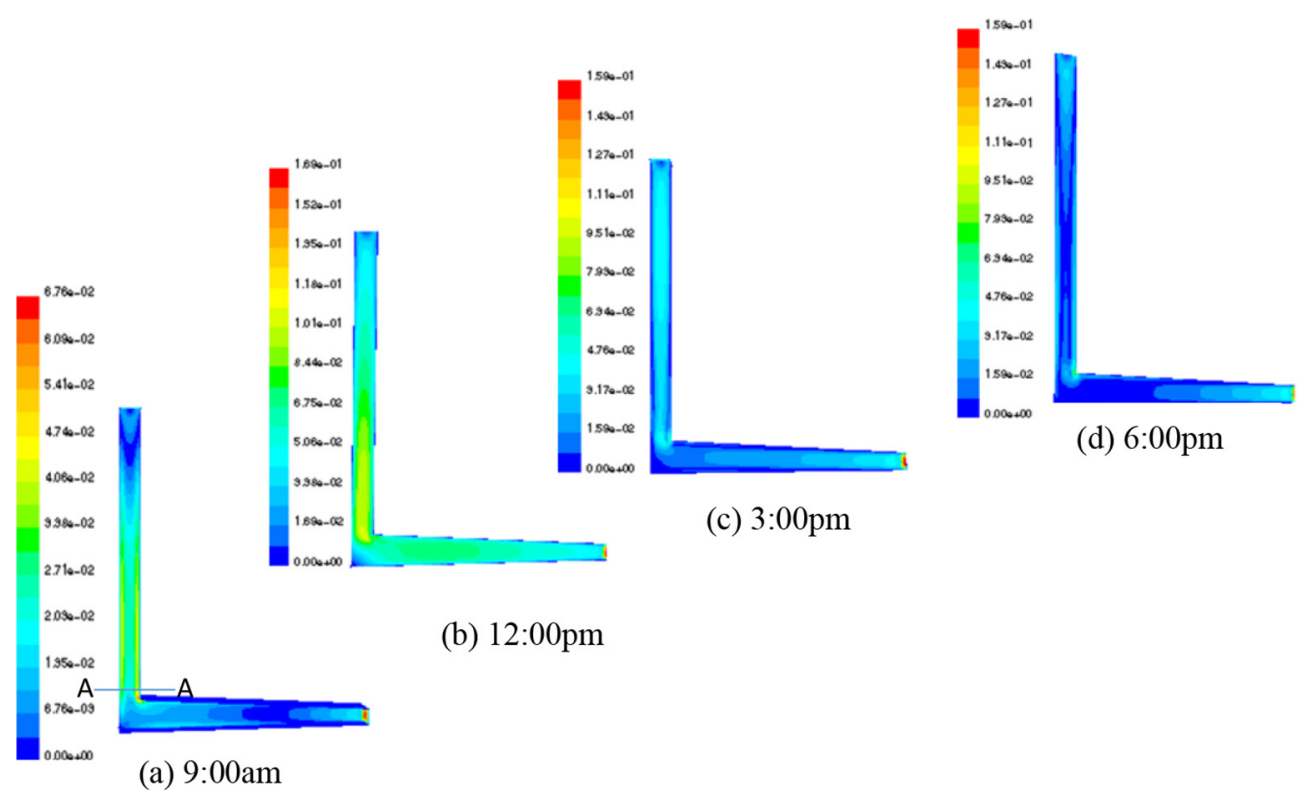

Figure 6: The velocity distribution in the collector and chimney for the stone material.

Figure 7 shows that the velocity magnitude increased within the chimney zone as a result of the increasing transfer of heat to the air from the energy storage in the ground materials. Noticeably, in section (A-A), the air-flow behavior changed as the range grew for the flow from the entrance length (developing profile) to fully developed. However, the sequence for the variable velocity at 9:00 am, 12:00 pm, and 3:00 pm was DGPW-stones-sawdust, stonesDGPW -ceramic, and stones-ceramic-pebbles, respectively.

It could be noted that there was an increase in the efficiency for the materials dark, green-painted wood DGPW, ceramic, black stones and sawdust, while Fig. 7d shows the values of the velocity at $6: 00 \mathrm{pm}$. The absorptivity of the solar thermal can be sequence as betterment of ceramic then stones and then pebbles. In conclusion, the ceramic material was the best material for the absorptivity and emissivity of energy during the length of the whole day.

\subsubsection{Temperature field}

The thermal field presented as temperature contours, Fig. 8, for each ground material, show that there was a change in the temperature distribution. Figure 8 shows the temperature distribution in the collector and the chimney with the ceramic basement at various times (9:00 am, 12:00 pm, 3:00 pm, and 6:00 pm).

Noticeably, for temperature and velocity, the maximum was recorded at 12:00 pm at the maximum intensity of $529.3 \mathrm{~W} / \mathrm{m}^{2}$, where the temperature was $40.25^{\circ} \mathrm{C}$ and the velocity was $0.67 \mathrm{~m} / \mathrm{s}$. Afterward, both factors decreased at the intensity below $320 \mathrm{~W} / \mathrm{m}^{2}$, as shown in Fig. 9. The figure illustrates the numerical and experimental results for the stones.

Figure 10 illustrates the results for both the numerical and experimental work on the ceramic material. The maximum temperature and velocity were $40.80^{\circ} \mathrm{C}$ and $0.69 \mathrm{~m} / \mathrm{s}$, 

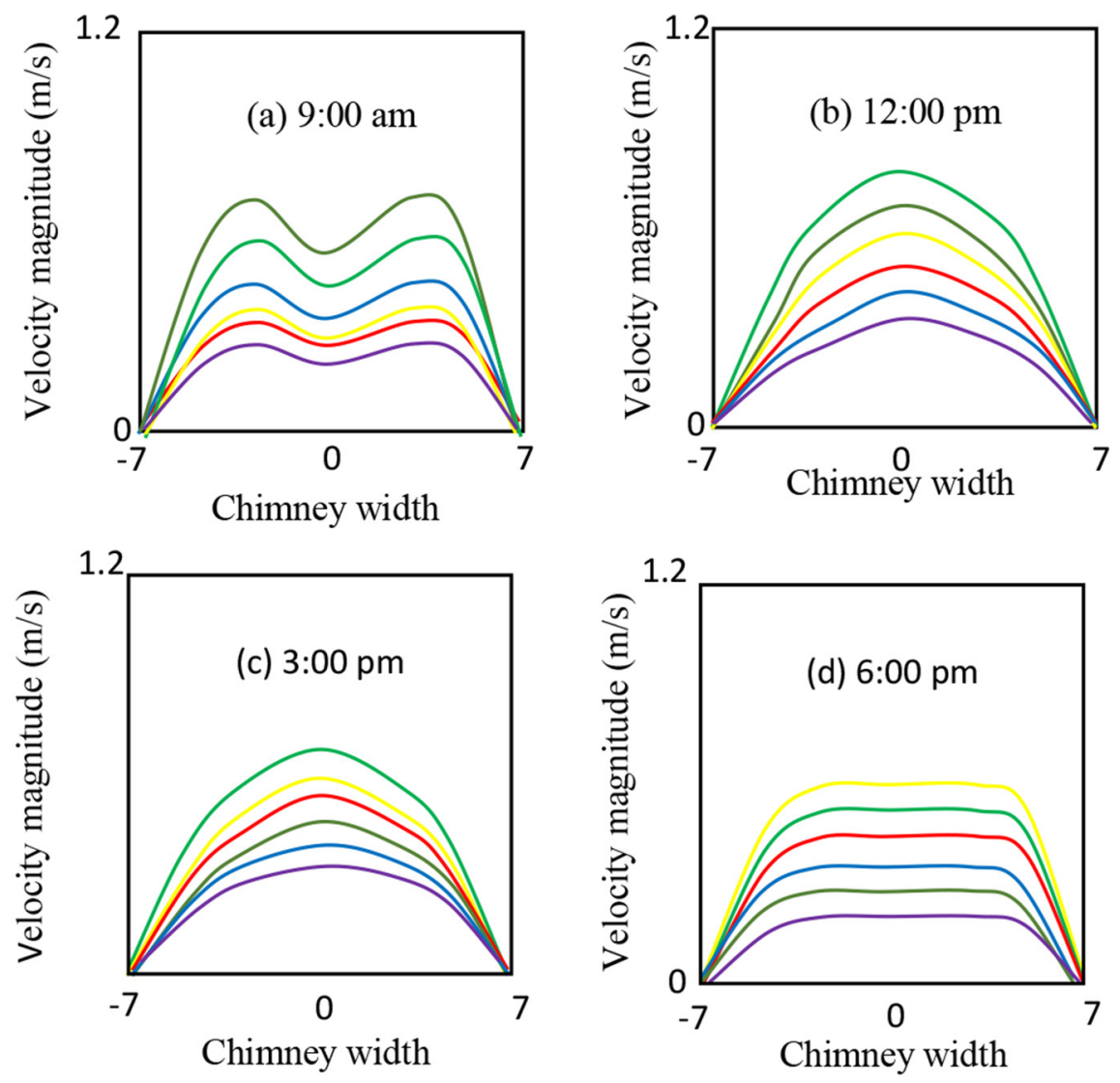

Saw dust

Fobble

Stone

\section{$\mathrm{DGPW}$}

Ceramic

Sand

Figure 7: The velocity distribution at section (A-A) in the inlet of the chimney at (9:00 am, 12:00 pm, 3:00 pm, and 6:00 pm).

respectively, at $12: 00 \mathrm{pm}$, with the maximum intensity of $529.3 \mathrm{~W} / \mathrm{m}^{2}$, which decreased to less than $320 \mathrm{~W} / \mathrm{m}^{2}$.

Table 5 shows the velocity outlet from the collector that was measured in the experimental work. As shown in the table, all the materials used in the simulation of the model, the numerical analysis is in good agreement with the experimental data, and the percentage error for the velocity was $5 \%-12 \%$.

Table 6 shows the temperature $\left({ }^{\circ} \mathrm{C}\right)$ outlet from the collector that was measured in the experimental work. For all the materials used in the simulation of the model, the percentage error was small $(2 \%-4 \%)$.

Considering the different materials investigated, the heat transfer coefficients in relation to convection between the ground and the air and radiation between the material and the cover are reported in Table 7 . The results inferred that higher convection heat transfer was experi- 

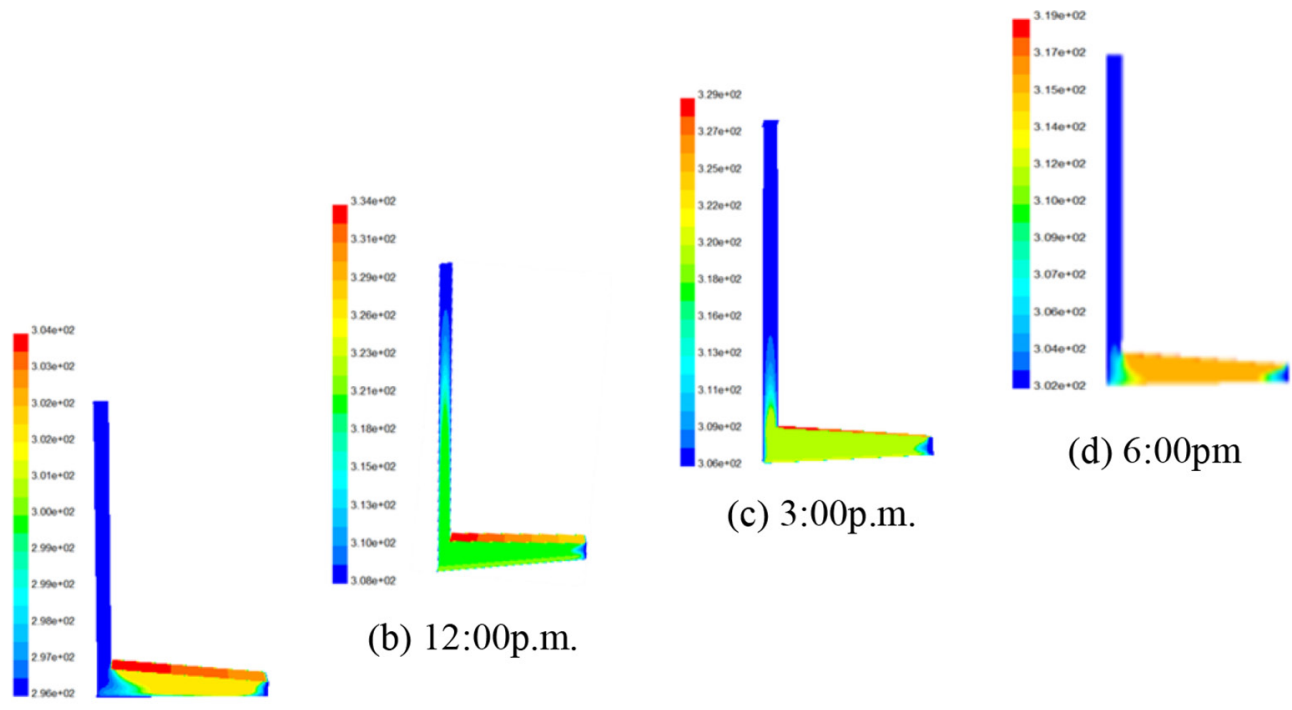

(c) 3:00p.m.

(b) 12:00p.m.

(a) 9:00a.m.

Figure 8: The temperature distribution counters for the ceramic.

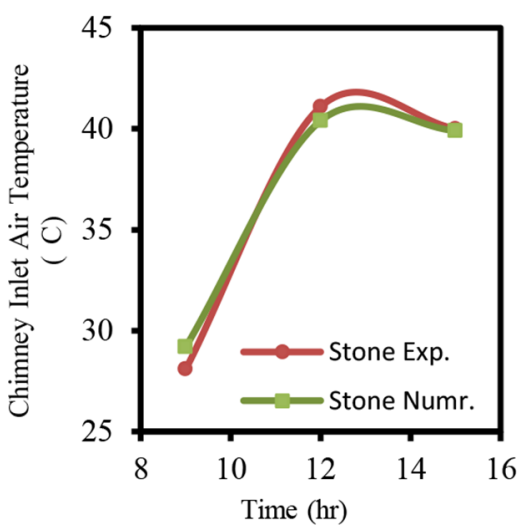

(a)Temperature

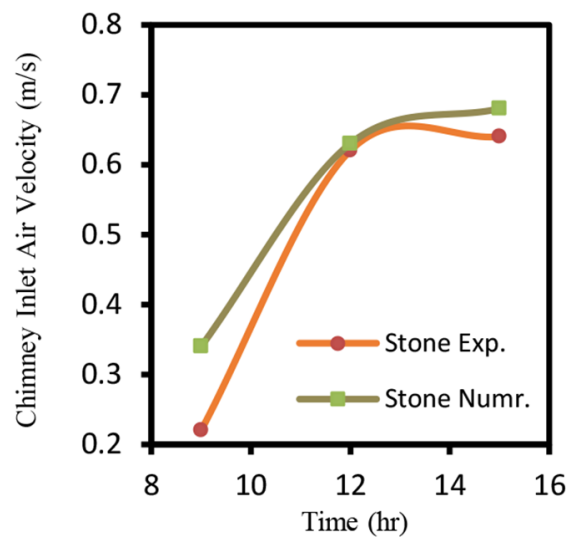

(b) Velocity

Figure 9: The temperature distribution and the velocity for the stone material at the inlet chimney.

enced with the materials which have low-heat penetration coefficient which leads to instant conversion of virtually the available solar energy to the material heat and instantly transferred to the air. High value of convective heat transfer coefficient contributes to higher thermal losses that can be seen in the low efficiency associated with the materials with low-heat penetration coefficient as shown in Fig. 4. Similarly, the materials with higher emissivity exhibited higher rate of heat transfer by radiation which is seen as in the case of ceramics, pebbles, stones and sand. 


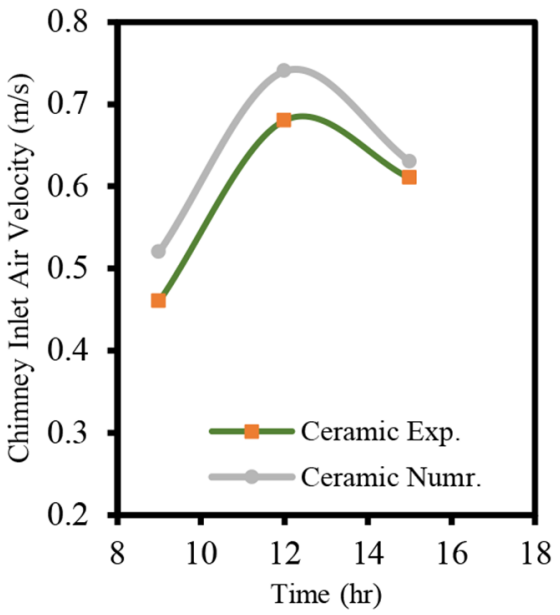

(a) Temperatures

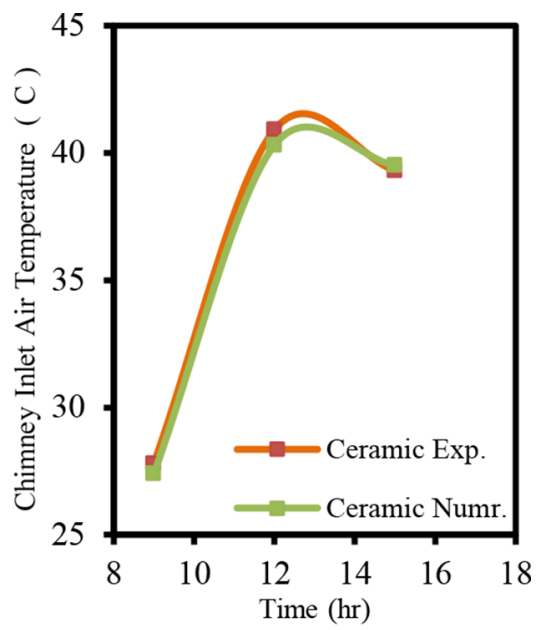

(b) Velocity

Figure 10: The temperature distribution and the velocity for the inlet chimney.

Table 5: The velocity $(\mathrm{m} / \mathrm{s})$ outlet from collector experimental and numerical.

\begin{tabular}{lccccccccc}
\hline & \multicolumn{2}{c}{$8: 00 \mathrm{am}$} & \multicolumn{2}{c}{$12: 00 \mathrm{pm}$} & \multicolumn{2}{c}{$16: 00 \mathrm{pm}$} & \multicolumn{2}{c}{$19: 00 \mathrm{pm}$} \\
\hline Materials & Exp. & Sim. & Exp. & Sim. & Exp. & Sim. & Exp. & Sim. \\
\hline Ceramic & 0.23 & 0.26 & 0.68 & 0.72 & 0.6 & 0.63 & 0.25 & 0.29 \\
Sand & 0.12 & 0.16 & 0.65 & 0.69 & 0.53 & 0.57 & 0.2 & 0.23 \\
Pebble & 0.19 & 0.22 & 0.67 & 0.71 & 0.58 & 0.61 & 0.28 & 0.31 \\
Saw Dust & 0.25 & 0.29 & 0.65 & 0.69 & 0.57 & 0.61 & 0.29 & 0.32 \\
Stone & 0.22 & 0.27 & 0.69 & 0.73 & 0.6 & 0.64 & 0.31 & 0.33 \\
D.G.P.W & 0.12 & 0.16 & 0.68 & 0.71 & 0.57 & 0.61 & 0.24 & 0.28 \\
\hline
\end{tabular}

\section{CONCLUSIONS}

This work presents the various performances of absorber materials that have different absorptivity properties. Six different materials, which are all locally available in Malaysia, were studied to determine the best material for solar radiation absorption and heat storage. The experimental study showed that the stone performed better during the day in terms of converting solar radiation into thermal energy and generating buoyant air in the system. From sunset to nighttime, the ceramic material performed better, which shows that higher energy is stored in the ceramics than in the stone material. The results showed that collector efficiency and operation time of the SCPP can be enhanced using the thermal storage system. The performance of the various materials showed that at midday, that is, from 12:00 pm to 3:00 pm, the stone material can store a considerable amount of energy that can be utilized during low-intensity hours to support nighttime operations. According to the mass flow rate generated in the system, the DGPW gave the best performance. The low-storage capacity of the DGPW resulted in increased energy instantly released into the air when the solar intensity is 
Table 6: The temperature $\left({ }^{\circ} \mathrm{C}\right)$ out let from the collector experimental and numerical.

\begin{tabular}{lcccccccc}
\hline & \multicolumn{2}{c}{$8: 00 \mathrm{am}$} & \multicolumn{2}{c}{$12: 00 \mathrm{pm}$} & \multicolumn{2}{c}{$16: 00 \mathrm{pm}$} & \multicolumn{2}{c}{$19: 00 \mathrm{pm}$} \\
\hline Materials & Exp. & Sim. & Exp. & Sim & Exp. & Sim. & Exp. & Sim \\
\hline Ceramic & 24.6 & 25.4 & 40.9 & 41.6 & 38.2 & 39.3 & 29.5 & 31.2 \\
Sand & 24.7 & 25.6 & 39.4 & 40.8 & 36.5 & 38.1 & 29.0 & 30.4 \\
Pebble & 25.0 & 25.6 & 40.7 & 40.9 & 37.6 & 38.0 & 29.5 & 30.8 \\
Saw Dust & 25.3 & 26.2 & 39.7 & 40.2 & 37.2 & 38.9 & 29.7 & 30.2 \\
Stone & 25.1 & 26.8 & 41.1 & 42.3 & 38.5 & 39.8 & 30.1 & 31.7 \\
D.G.P.W & 25.5 & 26.7 & 40.4 & 41.4 & 37.2 & 38.0 & 29.1 & 30.3 \\
\hline
\end{tabular}

Table 7: Convective and radiation heat transfer coefficients associated with the different materials to the air and cover respectively.

\begin{tabular}{lrrrrrrrrrrrrrrr}
\hline \multicolumn{2}{l}{ ceramic } & \multicolumn{4}{c}{} & \multicolumn{2}{c}{ Sawdust } & \multicolumn{2}{c}{ Stone } & \multicolumn{2}{c}{ Pebble } & \multicolumn{2}{c}{ Sand } & \multicolumn{2}{c}{ DGPW } \\
\hline Time & $\mathrm{h}_{\mathrm{c}}$ & $\mathrm{h}_{\mathrm{r}}$ & $\mathrm{h}_{\mathrm{c}}$ & $\mathrm{h}_{\mathrm{r}}$ & $\mathrm{h}_{\mathrm{c}}$ & $\mathrm{h}_{\mathrm{r}}$ & $\mathrm{h}_{\mathrm{c}}$ & $\mathrm{h}_{\mathrm{r}}$ & $\mathrm{h}_{\mathrm{c}}$ & $\mathrm{h}_{\mathrm{r}}$ & $\mathrm{h}_{\mathrm{c}}$ & $\mathrm{h}_{\mathrm{r}}$ \\
\hline $9: 00$ & 5.30 & 5.65 & 5.30 & 4.47 & 3.54 & 5.34 & 6.79 & 5.62 & 5.30 & 5.43 & 6.79 & 5.29 \\
$12: 00$ & 6.55 & 6.88 & 7.81 & 5.42 & 3.44 & 6.54 & 10.08 & 6.79 & 7.81 & 6.58 & 10.08 & 6.39 \\
$15: 00$ & 6.58 & 6.69 & 10.14 & 5.22 & 5.15 & 6.33 & 10.14 & 6.60 & 10.14 & 6.34 & 11.18 & 6.18 \\
$18: 00$ & 3.51 & 5.97 & 8.04 & 4.65 & 3.51 & 5.67 & 5.26 & 5.94 & 8.04 & 5.65 & 6.73 & 5.56 \\
\hline
\end{tabular}

high. The ceramics did not give a high-flow rate when the solar radiation intensity was high; rather, the energy was stored, and at night, it was constantly released to generate buoyant air with the highest flow rate. The numerical and experimental results were found to be in good agreement. The percentage errors for the velocity and temperature found after validating the numerical studies with the experimental studies were 5\%-12\% and $2 \%-4 \%$, respectively.

\section{REFERENCES}

[1] Haaf, W., Friedrich, K., Mayr, G. \& Schlaich, J., Solar chimneys part I: principle and construction of the pilot plant in Manzanares. International Journal of Solar Energy, 2, pp. 3-20, 1983. http://dx.doi.org/10.1080/01425918308909911

[2] Haaf, W., Solar chimneys, part II: preliminary test results from the Manzanares pilot plant. International Journal of Solar Energy, 2, pp. 141-161, 1984. http://dx.doi.org/10.1080/01425918408909921

[3] Schlaich, J., Bergermann, R., Schiel, W. \& Weinrebe, G., Design of commercial solar updraft tower systems - Utilization of solar induced convective flows for power generation. Journal of Solar Energy Engineering, Transactions of the ASME, 127, pp. 117124, 2005. 
[4] Chikere, A.O., Al-Kayiem, H.H. \& Karim, Z.A.A., Review on the enhancement techniques and introduction of an alternate enhancement technique of solar chimney power plant. Journal of Applied Sciences, 11, pp. 1877-1884, 2011. http://dx.doi.org/10.3923/jas.2011.1877.1884

[5] Al-Kayiem, H.H., Yin, K.Y. \& Sing, C.Y., Numerical simulation of solar chimney integrated with exhaust of thermal power plant. In Advanced Computational Methods and Experiments in Heat Transfer XII, B. Sundén, C.A. Brebbia, \& D. Poljak, Eds., WIT Press: United Kingdom, pp. 61-72, 2012. http://dx.doi.org/10.2495/HT120061

[6] Al-Kayiem, H.H., Energy sustainability through integrated solar thermal systems. WIT Transactions on Ecology and the Environment, 179, p. 11, 2013. http://dx.doi.org/10.2495/sc130752

[7] Shyia, A. Parametric study of solar chimney performance. M.Sc. thesis, University of AL-Mustansiriya, 2002.

[8] Kreetz, H., "Theoretische Untersuchungen und Auslegung eines temporaren Wasserspeichers fur das Aufwindkraftwerk." Diploma, Energieverfahrenstechnik und Umwandlungstechniken regenerativer Energien-EVUR, Technical University Berlin, Berlin, Germany, 1997.

[9] Bernardes, M.A.D.S., "Technische, ökonomische und ökologische Analyse von Aufwindkraftwerken (Technical, economic and environmental analysis of solar chimney power plants)," Universitätsbibliothek, 2004.

[10] Huang, H., Li, G. \& Zhang, H., Experimental performance of a solar collector in solar chimney power plant system. In Electrical and Control Engineering (ICECE), 2010 International Conference on, pp. 3718-3721, 2010. http://dx.doi.org/10.1109/icece.2010.907

[11] Miqdam, T.C. \& Hussein, A.K., Basement kind effects on air temperature of a solar chimney in Baghdad-Iraq Weather. International Journal of Applied Sciences, 2, pp. 12-20, 2011.

[12] Buğutekin, A., An Experimental investigation of the effect of periphery height and ground temperature changes on the solar chimney system. Isi Bilimi ve Teknigi Dergisi - Journal of Thermal Science and Technology, 32, pp. 51-58, 2012.

[13] Motsamai, O., Bafetanye, L., Mashaba, K. \& Kgaswane, O., Experimental investigation of solar chimney power plant. Journal of Energy and Power Engineering, 7, p. 1980, 2013.

[14] Pastohr, H., Kornadt, O. \& Gürlebeck, K., Numerical and analytical calculations of the temperature and flow field in the upwind power plant. International Journal of Energy Research, 28, pp. 495-510, 2004. http://dx.doi.org/10.1002/er.978

[15] Pretorius, J.P. \& Kröger, D.G., Critical evaluation of solar chimney power plant performance. Solar Energy, 80, pp. 535-544, 2006. http://dx.doi.org/10.1016/j.solener.2005.04.001

[16] Ming, T., Liu,W., Pan Y. \& Xu, G., Numerical analysis of flow and heat transfer characteristics in solar chimney power plants with energy storage layer. Energy Conversion and Management, 49, pp. 2872-2879, 2008. http://dx.doi.org/10.1016/j.enconman.2008.03.004 
[17] Zheng, Y., Ming, T.Z., Zhou, Z., Yu, X.F., Wang, H.Y. \& Pan,Y., Unsteady numerical simulation of solar chimney power plant system with energy storage layer. Journal of the Energy Institute, 83, pp. 86-92, 2010. http://dx.doi.org/10.1179/014426010X12682307291380

[18] Zhou, Y., Liu, X.H. \& Li, Q.L., Unsteady conjugate numerical simulation of the solar chimney power plant system with vertical heat collector. Presented at the 6th International Conference on Physical and Numerical Simulation of Materials Processing, ICPNS2010, Guilin, 2012.

[19] Hurtado, F.J., Kaiser, A.S. \& Zamora, B., Evaluation of the influence of soil thermal inertia on the performance of a solar chimney power plant. Energy, 47, pp. 213-224, 2012.

http://dx.doi.org/10.1016/j.energy.2012.09.040

[20] Azeemuddin, I., Al-Kayiem H.H. \& Gilani, S.I., Simulation of solar chimney power plant with an external heat source. In 4th International Conference on Energy and Environment 2013 (ICEE 2013), Putrajaya, Malaysia, pp. 1-4, 2013.

[21] Azeemuddin, I., Al-Kayiem, H.H \& Gilani, S.I., Simulation of a collector using waste heat energy in a solar chimney power plant system. In Sustainable City VIII, Putrajaya, Malaysia, pp. 933-944, 2013.

http://dx.doi.org/10.2495/sc130792

[22] Al-Azawie, S.S., Hassan S. \& Zammeri, M.F., Experimental and numerical study on ground material absorptivity for solar chimney power applications. In Energy and Sustainability V, vol. 186, Eds. H.H. Al-Kayiem, C.A. Brebbia \& S.S. Zubir, WIT Transactions on Ecology and The Environment: Putrajaya, Malaysia, pp. 219-230, 2014. http://dx.doi.org/10.2495/esus140191

[23] EngineeringToolbox, Thermophysical Properties of Stone, Pebble and Sawdust, available at http://www.engineeringtoolbox.com/density-solids-d_1265.html

[24] EngineeringToolbox, Thermophysical Properties of Ceramic, Sand and Wood, available at http://www.engineeringtoolbox.com/thermal-conductivity-d_429.html

[25] EngineeringToolbox, Properties of Stone, Pebble and Sawdust, available at http://www. engineeringtoolbox.com/specific-heat-solids-d_154.htm 